\title{
Urine analysis for glucose and protein: Are the requirements of the new contract sensible?
}

\author{
D Mant, G Fowler
}

One of the requirements of the 1990 terms of service for doctors in general practice is taking urine samples and analysing them for the presence of albumin and glucose as part of a health check. The health check is to be carried out when a patient aged over 5 years registers with a practice for the first time and every three years thereafter in patients aged 16-74 who have not consulted their general practitioner during that period. As there is no scientific justification for selective screening of people who do not consult their doctor there is also an implicit requirement for three yearly screening of patients who do consult. Presumably, the urine analysis is intended to be done with a dipstick.

The cost of urine analysis is not inconsiderable. A dipstick for analysing glucose and albumin costs about 10 pence, but there is also the cost of the urine container, of the time of the doctor or nurse, and of following up those with positive results. Even small costs become substantial when multiplied by 15 million (assuming triennial screening for adults aged 16-74). There are also other costs such as the inconvenience of obtaining and dealing with urine specimens.

Doubts have also been expressed about the clinical value of urinary screening for glucose and protein. The World Health Organisation study group on diabetes mellitus concluded in 1985 that "while routine urine testing remains an essential part of clinical examination of a patient, it is not appropriate for case finding." Keil and Moskowitz came to a similar conclusion for proteinuria: "There are no studies to support routine screening of asymptomatic individuals for proteinuria." A recent editorial, however, argued that routine analysis may be justified in certain situations, ${ }^{3}$ and it therefore seems timely to review the evidence for the value of screening urine analysis in general practice.

Imperial Cancer Research Fund General Practice Research Group,

University Department of Community Medicine and General Practice, Gibson

Building, Radcliffe

Infirmary, Oxford

OX2 6HE

D Mant, MRCGP, clinical

lecturer in general practice

G Fowler, FRCGP, reqder in general practice

Correspondence to: $\mathrm{Dr}$ Mant.

Br.Med f 1990;300:1053-5 however, no evidence exists showing that early detection and treatment of asymptomatic diabetes or impaired glucose tolerance will reduce the risk of microvascular or macrovascular complications-or, in the case of impaired glucose tolerance, deterioration to diabetes.

Screening for proteinuria-Protein in the urine is derived from excreted plasma proteins or from the renal and genital tract. Commonly, proteinuria is transient and benign-that is, related to exercise, posture, or minor illness-or is associated with a urinary tract infection. ${ }^{2}$ It rarely indicates an early renal or haematological disease that requires treatment or careful surveillance for the onset of treatable complications. Moreover, the value of discovering asymptomatic infections of the renal tract remains debatable. An extensive review concluded that most studies of long term follow up of asymptomatic bacteriuria had not shown a decrease in renal function in otherwise healthy individuals and that screening and treatment should be restricted to specific high risk groups such as those with abnormalities of the renal tract or with compromising medical conditions. ${ }^{4}$

\section{Previous experience of screening for glycosuria}

The maximum potential benefit of screening can be assessed from the empirical data reported by previous studies. Six community surveys (mostly based on general practice lists) in which patients have been tested for glycosuria were reported in the early $1960 \mathrm{~s}^{5-10}$ The table shows the results of three studies reporting age stratified results. In each case the urine was tested initially by Clinistix (Ames, Stoke Poges). The criteria for diagnosing diabetes was a fasting blood glucose concentration $>6.7 \mathrm{mmol} / 1,{ }^{10}$ a Harrison diabetic type glucose tolerance test, ${ }^{510}$ or a fasting blood glucose concentration $>6.7 \mathrm{mmol} / 1$ two hours after a $50 \mathrm{~g}$ glucose meal. ${ }^{8}$ The predictive value of a positive test is very low in patients aged $<40$, but in those aged $\geqslant 60$ it is about one in three-which may be acceptable for a screening test. At the most, however, $2 \cdot 4 \%$ of those of diabetes for many years only to present with screened had positive results and the yield would be
complications of the disease. To our knowledge, expected to be much lower (perhaps fivefold) on of diabetes for many years only to present with screened had positive results and the yield would be
complications of the disease. To our knowledge, expected to be much lower (perhaps fivefold) on

Results of three studies of diabetes in the community: prevalence of glycosuria and undiagnosed diabetes according to age

\begin{tabular}{|c|c|c|c|c|c|c|c|c|c|}
\hline \multirow[b]{2}{*}{$\begin{array}{l}\text { Age } \\
\text { (years) }\end{array}$} & \multicolumn{3}{|c|}{ Newcastle upon Tyne' } & \multicolumn{3}{|c|}{ Essex $^{10}$} & \multicolumn{3}{|c|}{ Bedford $^{*}$} \\
\hline & $\begin{array}{c}\text { No of } \\
\text { patients }\end{array}$ & $\begin{array}{l}\% \text { With } \\
\text { glycosuria }\end{array}$ & $\begin{array}{l}\% \text { With previously } \\
\text { undiagnosed diabetes }\end{array}$ & $\begin{array}{c}\text { No of } \\
\text { patients }\end{array}$ & $\begin{array}{l}\text { \% With } \\
\text { glycosuria }\end{array}$ & $\begin{array}{l}\text { \% With previously } \\
\text { undiagnosed diabetes }\end{array}$ & $\begin{array}{c}\text { No of } \\
\text { patients }\end{array}$ & $\begin{array}{l}\% \text { With } \\
\text { glycosuria }\end{array}$ & $\begin{array}{l}\text { \% With previously } \\
\text { undiagnosed diabetes }\end{array}$ \\
\hline$<40$ & 1238 & & $0 \cdot 1$ & 2991 & 1.6 & & 9451 & 3.6 & 0.3 \\
\hline $40-59$ & 503 & & 0.6 & 1581 & $3 \cdot 8$ & 0.6 & 10469 & 3.9 & $1 \cdot 1$ \\
\hline$>60$ & 250 & & $2 \cdot 4$ & 1231 & $6 \cdot 7$ & $2 \cdot 0$ & 5433 & $5 \cdot 2$ & $2 \cdot 0$ \\
\hline
\end{tabular}


subsequent screenings at three yearly intervals. More positive results and a lower predictive value were found in men than in women.

Three subsequent studies from general practice have been an extension of the practices' activities and may reflect better what might happen in the average practice. ${ }^{11-13}$ Unfortunately, only one of them can be considered reliable, ${ }^{11}$ but the three studies reported finding glycosuria with a dipstick in $2 \cdot 1 \%, 1 \cdot 0 \%$, and $1.5 \%$ of patients, with the proportion of new diabetic subjects identified being $0 \cdot 2 \%, 0 \cdot 3 \%$, and $0.5 \%$ respectively. Again, these figures were based on a single (prevalence) screening. A recent study from a practice which attempted to supplement a case finding approach by screening for glycosuria found three diabetic subjects (fasting blood glucose concentration $>7 \mathrm{mmol} / \mathrm{l}$ ) from 572 attenders - a yield of $0.5 \% .^{14}$

A study by the Royal College of General Practitioners in Birmingham assessed the sensitivity and specificity of urine analysis for glycosuria. ${ }^{6}$ For clinical diabetes glycosuria is virtually $100 \%$ sensitive, and it is also reasonably specific $(98 \%)$ despite the large variation in renal thresholds. A high specificity, however, does not guarantee a high predictive value in a community setting where prevalence of the disease is low and only one in nine patients $(11 \%)$ positive on testing had clinical diabetes (fasting blood glucose concentration $>10 \mathrm{mmol} / \mathrm{l})$.

\section{Previous experience of screening for proteinuria}

Assessing the immediate outcome of screening for proteinuria is rather more difficult as there have been few well conducted community based studies. The best study from general practice is one in which 47 of 4061 patients $(1 \cdot 1 \%)$ were found to have significant albuminuria (positive result by Albustix (Ames, Stoke Poges) and salicylsulphonic acid test),, 1 but new chronic systemic disease was found in only one patient, who had chronic lymphatic leukaemia. The only important urinary tract disease discovered was infection, and in five patients this was described as pyelitis or nephritis. Another study reported a higher proportion of proteinuria $(56 / 654,8.6 \%)$ based only on dipstick analysis and identified 10 urinary tract infections but no other disease (although testing for haematuria in the same population showed that one patient had a bladder tumour). ${ }^{12}$ Coltman noted that more than half of the 95 patients $(5 \cdot 6 \%)$ with proteinuria were suffering from urinary tract infections. ${ }^{13}$ Although she claimed to have identified several other conditions, including hypertension, bladder tumour, cardiorenal failure, renal calculus, diabetes mellitus, rheumatoid arthritis, myeloma, and duplex kidney, she did not state whether these conditions were already known or how the diagnosis and the causative association were confirmed.

Interpreting these studies is difficult because of differences in the populations screened, the definition of a positive test for protein, and the definition of a previously unknown significant disease, but they do allow the yield of the screening to be estimated. Previously unrecognised treatable disease other than acute infection was found in 1 in 5000 patients $^{11}$ and urinary tract infection in between 1 in 30 and 1 in 500 . Once again, it must be emphasised that these estimates are based on only one screen.

No data are available to assess the sensitivity and specificity of dipstick testing for protein to detect serious treatable non-infectious disease. The sensitivity for detecting urinary infection, however, has been assessed as $36 \% .^{15}$ The specificity depends on the threshold taken as positive, and we have found no data for protein analysis alone. The sensitivity and specificity for combined protein and blood testing, however, are reported as $70 \%$ and $71 \%$ respectively when proteinuria was defined as a trace of protein or more and $62 \%$ and $79 \%$ when it was defined as + or more. ${ }^{16}$ The predictive value of proteinuria for unrecognised urinary infection in the general practice studies was $17 \% .^{112}$

\section{Screening in other settings}

The results of screening in other settings must be extrapolated to general practice with caution because the yield and predictive value are dependent on the prevalence of the disease in the population screened. Nevertheless, several studies conducted outside the United Kingdom merit attention. The variable number of positive results for proteinuria seen in general practices in the United Kingdom is also seen in other community settings. In Sweden 3998 men and women from an unselected population of 7090 were screened for urinary protein and proteinuria was found in $13 \%$ of those screened. ${ }^{17}$ In Israel 21000 healthy employed adults of working age (96\% aged 20-65) were screened and proteinuria was detected in $3.9 \%$ of women and $4.9 \%$ of men. ${ }^{18}$ One reason for the variation in yield could be the definition of proteinuria. A hospital based study in South Australia found albuminuria in $9.9 \%$ of those screened when it was defined as trace or more, in $0.8 \%$ when it was defined as + or more, and in $0.6 \%$ when it was defined as ++ or more. ${ }^{19}$

A further study from Israel, although based on microscopic examination for cells rather than dipstick analysis, indicates the effect of repeat testing for urinary abnormality in a healthy population. When 1000 air force staff were screened by microscopy annually over a period of 15 years, $39 \%$ had at least one positive test result for haematuria ${ }^{14}$ and $32 \%$ had one positive result for leucocyturia. ${ }^{20}$ After 15 years all subjects were active and free of urinary symptoms and only two patients had been found to have serious diseases; one had focal glomerulonephritis and the other bladder calculus. Another patient had cancer of the urinary tract, but this was diagnosed by clinical symptoms rather than by the results of screening.

Finally, even in a hospital setting the yield of unrecognised treatable disease has been low. A hospital outpatient department in Nottingham tested 5886 patients by dipstick for glucose, protein, and blood in the urine and $30(0.5 \%)$ patients were found to have a previously undiagnosed disease; the diagnosis in one patient with polycystic kidney disease and one with hypertensive nephrosclerosis could probably be attributed to finding a proteinuria alone..$^{21}$

\section{Quality control}

Despite the apparent simplicity of urine analysis quality control assessments have shown poor reliability in several clinical settings. Dipstick analyses of three urine specimens sent to 66 wards and clinics in one hospital's quality control study showed false positive rates of $5 \%$ for protein estimation and $13 \%$ for glucose estimation and false negative rates of $5 \%$ and $10 \% .22$ Similarly, in a South Australian screening programme in which screeners were asked to categorise a urine specimen standard containing protein $1+$ and glucose trace, incorrect results were recorded by $19 \%$ of screeners for protein and $72 \%$ for glucose. ${ }^{23}$ False negative results for protein and glucose were recorded by $9 \%$ of screeners.

\section{Practical outcome}

One repeated criticism of urine analysis screening is that doctors take little notice of the results. Of 2024 
patients who underwent urine analysis when they were admitted to hospital in Australia, 4\% exhibited unexpectedly abnormal results, but in only one third of these was the attending doctor aware of the results and fewer than one fifth had a further diagnostic test. ${ }^{24}$ None of the patients' treatments were altered. A study in Vancouver reported that action was taken on fewer than half of the abnormalities found through routine urine analysis at admission, ${ }^{25}$ and one in California, reported that in only one of 123 patients who underwent routinely ordered urine analysis was necessary treatment started. ${ }^{26}$ In another study abnormalities were ignored by doctors in one third of the patients with glycosuria and two thirds of those with proteinuria. ${ }^{23}$ In general, this was either because the cause was thought to be artefactual or because the diagnosis was already clear. In only one case of proteinuria did the findings lead to a reassessment of the diagnosis.

\section{Alternative tests}

It could be argued that the government has chosen the wrong tests, and if its aim is to detect hidden urinary tract infections this is certainly true. Zilva concluded in a review in 1985 that slight proteinuria is an unspecific finding of no diagnostic importance and that simple urine microscopy is much more useful for diagnosing infection and chronic renal disease. ${ }^{27}$ Dobbs and Fleming ${ }^{15}$ illustrated that dipstick testing for blood was more sensitive and testing for nitrite was both more sensitive and more specific than testing for protein in detecting urinary tract infections that had been established by culture. A more recent study in the elderly, showed that dipstick urine analysis for nitrite and leucocyte esterase gave a sensitivity of $90 \%$ and a specificity of $70 \% .^{28}$ The comparable sensitivity for protein testing is less than $40 \%$, and, although adding protein estimation to the measurement of nitrite and leucocyte esterase increased sensitivity to $97 \%$, the specificity was reduced to $34 \%$.

Testing for haematuria is also likely to identify more renal tract infections than testing for proteinuria. The problems of high cumulative positive rates and low predictive values, however, are common to both tests. In a population based survey at the Mayo Clinic of men and women aged $\geqslant 35$ between 1972 and $1978,13 \%$ had asymptomatic haematuria..$^{29}$ Of these, only $2 \cdot 3 \%$ had serious disease-a predictive value of $18 \%$. Most patients with false positive results had undergone invasive investigations. Ritchie reported that 303 of 10050 men being screened by the British United Provident Association in the United Kingdom had positive results by dipstick testing $(3 \%)^{30}$; the results of 255 of these patients were confirmed by further testing. Of the 152 patients who could be traced, 59 had had no further investigation and five had had serious disease (bladder neoplasia (two patients), epithelial dysplasia, renal calculus, and chronic reflux). It is difficult to calculate a sensible predictive value with so much missing data, but it is probably between $2 \%$ and $7 \%$. Finally, in a recently reported screening study in the elderly, $123(23 \%)$ of 578 men aged $\geqslant 60$ had postitive test results for haematuria in at least one of 10 weekly urine tests by dipstick. ${ }^{31}$ Of 87 investigated, 45 had some form of urological disease and four had treatable bladder tumours - a predictive value for tumours of $3-5 \%$. So, although screening for haematuria may show more serious disease, it has a very high cost in terms of unnecessary investigation and there is no firm evidence that the earlier detection of renal disease by screening has appreciably beneficial effect on outcome.

\section{Conclusion}

There are four good reasons why the contractual requirement to screen unselectively is not appropriate: there is no clear objective for screening for proteinuria, screening for glycosuria or proteinuria does not reduce morbidity or mortality, the cost of screening in terms of unnecessary investigation is high, and quality control and follow up are likely to be poor.

Urine analysis for glucose remains an essential part of the clinical examination and may prevent doctors from missing a diagnosis of diabetes mellitus. ${ }^{32}$ But Zilva is clearly correct to conclude that "unselective urine testing is a waste of resources and, as often practised, frequently yields misleading results that are ignored or misinterpreted." 27 Professional consensus could be achieved on the value of selective screening of patients at high risk, such as the elderly. The debate must centre on the definition of high risk groups, the most effective method of screening, and the appropriate clinical management of patients with positive test results. The task is to encourage urine analysis in patients in whom it is indicated. ${ }^{3}$ A contractual requirement for unselective screening for urinary protein and glucose will only undermine this objective.

1 World Health Organisation. Diabetes mellitus. WHO Tech Rep Ser 1985:727. 2 Kiel DP, Moskowitz MA. The urinalysis: a critical appraisal. Med Clin North Am 1987;71:607-24.

3 Rasmussen OV, Lopez J, Udsen P, Espersen O. Is routine urinalysis worthwhile? Lancet 1988;i:747-8.

4 Shortliffe DLM. Asymptomatic bacteriuria: should it be treated? Urology $1986 ; 27$ (suppl): $19-25$.

5 Redhead MD. Incidence of glycosuria and diabetes mellitus in a general practice. Br Med F 1960;i:695-9.

6 Working party appointed by The College of General Practitioners. A diabetes survey. Br Med f 1962;ii: 1497-503.

7 Stewart W, Robertson P. Detection of diabetes mellitus under population survey conditions. Lancet 1963;ii:184-7.

8 Butterfield W. Summary of results of the Bedford diabetes survey. Proceedings of the Royal Society of Medicine 1964;57:196-200.

9 Walker J, Kerridge D. Community survey of diabetes. Br Med I 1962;i:381.

10 Harkness J. Prevalence of glycosuria and diabetes mellitus. Br Med $f$ 1962;ii: $1503-7$.

11 Baddeley $\mathrm{H}$, Baddeley $\mathrm{H}$, Sell FK. Mass urinalysis in general practice. Lance 1964;: $925-6$

12 Elliott P. Urine Screening. Experience of urine screening in general practice. Focus on urine analysis. Oxford: Medicine Publishing Foundation, 1983

13 Coltman KD. Urinary screening in general practice. Practitioner 1981;225: 668-72.

14 Fairley R. How effective is case finding at detecting diabetes and hypertension in the community? Br Med f 1987;294:1202.

15 Dobbs FF, Fleming DM. A simple scoring system for evaluating symptoms, history and urine dipstick testing in the diagnosis of urinary tract infection I R Coll Gen Pract 1987;37:100-4.

16 Shaw ST, Poon SY, Wong ET. Routine analysis-is the dipstick enough? ЭAMA 1985;253:1596-600.

17 Alwall N, Lohi A. A population study of renal and urinary tract diseases. Acta Med Scand 1973;194:525-47.

18 Carel RS, Silverberg DS, Kaminsky R, Aviram A. Routine urinalysis (dipstick) findings in mass screening of healthy adults. Clin Chem 1987;33:2106-8

19 Froom P, Ribak J, Benbassat J. Significance of microhaematuria in young adults. Br Med f 1984;288:20-2.

20 Benbassat J, Froom P, Feldman M, Margaliot S. The importance of leukocyturia in young adults. Arch Intern Med 1985; 145:79-80.

21 Morgan AG. Is routine urine testing in outpatient clinics useful? $\mathrm{Br} \mathrm{Med}$ 1988;297:1173.

22 Simpson E, Thompson D. An assessment of hospital routine analysis. Clin Chem 1978:24:389-90.

23 Fraser CG. Urine analysis: current performance strategies for improvement. BrMed F 1985;291:321-2.

24 Del Mar C, Badger P. The place of routine urine testing on admission to hospital. Med F A ust 1989;151:151-3

25 Heimann GA, Frohlich J, Bernstein M. Physicians' response to abnorma results of routine urinalysis. Can Med Assoc $\mathcal{F}$ 1976;115:1094-5.

26 Akin BV, Hubbell FA, Frye EB, Rucker L, Friis R. Efficacy of the routin admission of urinalysis. Am F Med 1987;82:719-22.

27 Zilva JF. Is unselective biochemical urine testing cost effective? $\mathrm{Br} \mathrm{Med} \mathcal{f}$ 1985;291:323-5.

28 Flanagan PG, Davies EA, Rooney PG, Stout RW. Evaluation of fou screening tests for bacteriuria in elderly people. Lancet 1989;i:1117-9.

$29 \mathrm{Mohr}$ DN, Offord KP, Owen RA, Melton LJ. Asymptomatic microhematuria and urologic disease RAMA 1986;256.2249.

30 Ritchie CD, Bevan EA, Collier St J. Importance of occult haematuria found at screening. Br.Med f 1986;292:681-3.

31 Britton JP, Dowell A, Whelan P. Dipstick haematuria and bladder cancer in men over 60: results of a community study. Br Med f 1989;299:1010-2 32 Hughes JT. Routine urinalysis. Lancet 1988;i:1112-3.

(Accepted 15 March 1990) 